\title{
Configurações
}

Revista de sociologia

$24 \mid 2019$

Imaginar "futuros" do trabalho, contextos e vivências subjetivas

\section{O trabalho e o sexo como objectos de regulação: contributo para o estudo cultural do direito}

Labour and sex as objects of regulation: contribution to the cultural study of law Le travail et le sexe comme objets de régulation: contribution à l'étude culturelle du droit

\section{Tiago Ribeiro}

\section{(2) OpenEdition Journals \\ Edição electrónica \\ URL: http://journals.openedition.org/configuracoes/7746 \\ DOI: $10.4000 /$ configuracoes. 7746 \\ ISSN: 2182-7419 \\ Editora \\ Centro de Investigação em Ciências Sociais \\ Edição impressa \\ Paginação: 79-95 \\ ISSN: 1646-5075 \\ Refêrencia eletrónica \\ Tiago Ribeiro, « O trabalho e o sexo como objectos de regulação: contributo para o estudo cultural do direito », Configurações [Online], 24 | 2019, posto online no dia 18 dezembro 2019, consultado o 19 dezembro 2019. URL : http://journals.openedition.org/configuracoes/7746 ; DOI : 10.4000/ configuracoes. 7746}


Ribeiro, Tiago - 0 trabalho e o sexo como objectos de regulação: contributo para o estudo cultural do direito. Configurações, vol. 24, 2019, pp. 79-95.

\title{
0 trabalho e o sexo como objectos de regulação: contributo para o estudo cultural do direito'
}

\author{
TIAGO RIBEIRO*
}

Centro de Estudos Sociais - Faculdade de Economia da Universidade de Coimbra

\begin{abstract}
Resumo
Este artigo procura estabelecer um diálogo heurístico entre as lógicas normativas de mercadorização do trabalho e as lógicas normativas de psiquiatrização do sexo. A partir de uma incursão crítica por um conjunto de protocolos morais e periciais que servem a descrição e a regulação do trabalho e da sexualidade, este ensaio tem por objectivo contribuir para sinalizar velhas e novas articulações entre desvio, normalidade e sentido. Apoiando-se em modos específicos de produção de verdade e de justiça, a mercadorização do trabalho e a psiquiatrização do sexo revelam uma afinidade epistémico-funcional no governo jurídico do sujeito que interpela as bases culturais do direito como fenómeno social.
\end{abstract}

Palavras-chave: direito; trabalho; sexualidade; mercado; psiquiatria.

\begin{abstract}
Labour and sex as objects of regulation: contribution to the cultural study of law

This article aims to establish a heuristic dialogue between normative logics of labour commodification and normative logics of the psychiatrisation of sex. From a critical incursion into a set of moral and expert protocols that serve the description and regulation of labour and sex, this essay aims to contribute to the identification of old and new articulations between deviation, normality and meaning. Relying on specific modes of production of truth and justice, the commodification of labour and the psychiatrisation

1 Este texto resulta do trabalho de investigação desenvolvido no âmbito do projecto de doutoramento em Sociologia, financiado pela Fundação para a Ciência e Tecnologia (com a referência SFRH/ $\mathrm{BD} / 105231 / 2014)$.

*E-mail: tiagor@ces.uc.pt
\end{abstract}


of sex reveal an epistemic-functional affinity in the juridical government of the subject that questions the cultural bases of law as a social phenomenon.

Keywords: law; labour; sex; market; psychiatry.

\begin{abstract}
Résumé
Le travail et le sexe comme objets de régulation: contribution à l'étude culturelle du droit

Cet article cherche à établir un dialogue heuristique entre les logiques normatives de la marchandisation du travail et les logiques normatives de la psychiatrisation du sexe. Partant d'une incursion critique à travers un ensemble de protocoles moraux et d'experts servant à décrire et à réguler le travail et la sexualité, cet essai vise à contribuer à l'identification d'anciennes et de nouvelles articulations entre déviation, normalité et signification. En s'appuyant sur des modes de production spécifiques de vérité et de justice, la marchandisation du travail et la psychiatrisation du sexe révèlent une affinité épistémique et fonctionnelle dans le gouvernement juridique du sujet qui remet en question les fondements culturels du droit en tant que phénomène social.
\end{abstract}

Mots-clés: droit; travail; sexualité marché; psychiatrie.

\title{
1. 0 trabalho e o sexo como potencialidade analítica
}

Este artigo procura ensaiar um conjunto de pistas de reflexão em torno do governo das pessoas e das coisas, fazendo do direito um observatório sociológico e tirando partido de um diálogo heurístico entre lógicas de mercadorização do trabalho e lógicas de psiquiatrização do sexo. O trabalho e o sexo constituem esferas de vida ou domínios de sentido cuja relação funcional e simbólica mereceu atenção na teoria social, a partir de diferentes autores e perspectivas. Quando Georges Bataille, por exemplo, propõe uma interpretação do erotismo a partir da relação entre trabalho e recreio, alega que "se ao querer compreender o homem em geral eu quiser compreender o erotismo em particular, uma primeira obrigação me é imposta: tenho de começar por conceder ao trabalho o primeiro lugar” (Bataille, 2012: 35). No mesmo sentido prossegue Jacques Derrida, cujo esforço desconstrutivo da noção de deboche se traduz no apelo para que "não esqueçamos o seu sentido inicial, [pois] significa o não-trabalho, a interrupção do labor, um certo desemprego, uma crise da contratação [embauche] ou do direito ao trabalho, mas também, e consequentemente, o lúdico e o lúbrico, o impúdico, a luxúria, o descaramento, a libertinagem, a licenciosidade" (Derrida, 2009: 68). Enquanto movimentos de natureza epistémico-pericial e ideológico-moral, o mercado, como expressão de uma racionalidade económico-governamental de que Michel Foucault se 
ocupou em Nascimento da biopolítica (2010), e a psiquiatria, enquanto expressão de uma racionalidade cognitivo-disciplinar que o mesmo autor desenvolveu no primeiro volume da História da sexualidade: vontade de saber (1994), funcionam como fontes de verdade que sustentaram historicamente a produção de justiça.

Tal significa que esse consenso económico e que esse consenso psiquiátrico se forjaram como campos periciais com poder constituinte e normativo, isto é, controlam a presunção jurídica do que é ou não é aquilo que designam por trabalho, do que é ou não é aquilo que designam por sexo, e modelam a prescrição jurídica do que deve ou não deve ser o trabalho, do que deve ou não deve ser o sexo. Desse ponto de vista, o trabalho e o sexo, enquanto tal, não existem fora de um regime de produção de sentido que confere existência normativa ao seu sujeito (o que são e o que fazem as pessoas?), à sua matéria (como são o que são e como fazem o que fazem?), e ao seu estatuto (por que é que as pessoas são o que são e por que é que fazem o que fazem?). Vejamos um exemplo comparado:

- um trabalhador é inadaptado (o que pode justificar o seu despedimento) porque se presume que haja alguém que é adaptado para o efeito, porque se criaram dispositivos de verificação da categoria laboral adaptação, porque se concebeu que aquilo que ela exprime é matéria potencialmente relevante, e portanto porque o modo de descrever e significar essa realidade a torna objecto de tutela normativa;

- um sujeito é pedófilo (o que pode justificar uma medida de segurança) porque se presume que haja alguém que não o é, porque se criaram dispositivos de verificação da categoria psiquiátrica pedofilia, porque se concebeu que aquilo que ela exprime é matéria potencialmente perigosa, e portanto porque o modo de descrever e significar essa realidade a torna objecto de tutela normativa.

A hipótese de que o mercado hegemonizou a definição do que é verdadeiro, possível e desejável no trabalho (Supiot, 2005; Amado, 2013), tal como a psiquiatria hegemonizou a definição do que é verdadeiro, possível e desejável na sexualidade (Bayer, 1987; Weeks, 1991), não deixa de devolver resultados surpreendentes quando olhamos para o modo como estes processos, que nasceram com vocações distintas e que viveram percursos próprios ao longo do tempo, converteram o trabalho e a sexualidade em objectos reveladores de uma afinidade epistemológico-funcional entre as respectivas gramáticas de leitura e de normação da realidade social.

A relação do trabalho com o mercado e a relação do sexo com a psiquiatria encontram um denominador comum no conceito de austeridade: se, no primeiro caso, surge como resultado da radicalização do paradigma neoliberal (Blyth, 2013; Streeck e Schäfer, 2013), no segundo caso remonta ao modelo biodisciplinar vitoriano (Lebrun, 1983; Foucault, 1994). Partilham ainda, e pelo menos, cinco características que importa colocar em perspectiva confluente: 
- em primeiro lugar, ambos se organizam ou podem ser lidos a partir de um princípio de utilidade: o primeiro, sob o imperativo generativo de valor; o segundo, sob o imperativo generativo de vida;

- em segundo lugar, idealizaram um sujeito-tipo: o primeiro, um sujeito dócil (versão subordinada) e empreendedor (versão empenhada); o segundo, um sujeito saudável e procriativo;

- em terceiro lugar, segregaram o seu próprio lúmpen, isto é, a sua forma activa de não existência ${ }^{2}$ (Santos, 2003): o primeiro, o sujeito improdutivo e preguiçoso (cf. Lafargue, 2016); o segundo, o sujeito degenerado e anormal (cf. Foucault, 2001);

- em quarto lugar, o mundo laboral e o mundo sexual foram autonomizados e fronteirizados enquanto esferas específicas da vida jurídico-social e convertidas em objecto tanto de antagonismo político quanto de monopolização pericial, de que resultam influências mútuas;

- finalmente, em quinto lugar, trabalho e sexualidade são territórios sociais que se encontram progressivamente submetidos tanto a uma vigilância panóptica como a aproximações terapêuticas (Standing, 2014: 236-274; Wacquant, 2009: 209-242).

Este conjunto de características confluentes entre o trabalho e a sexualidade traz consigo algumas interrogações de maior alcance: quais os dispositivos de governo e o repertório de saberes jurídico-judiciários (cf. Hunt e Wickham, 1994) a partir dos quais opera essa regulação normativa e cognitiva? como se constituem sujeitos individuais e colectivos a partir dessa matriz de governamentalidade (Foucault, 2009)? qual a relação de cada um desses regimes de austeridade entre si, tendo em conta o horizonte cruzado que a psicologização do governo do trabalho (Sennett, 2001) e a mercadorização do governo da sexualidade (Preciado, 2013) revelam? Olhemos primeiro para o trabalho - objecto primordial da coligação do direito com o mercado - e seguidamente para o sexo - objecto primordial da coligação do direito com a psiquiatria -, para depois, inspirados pelas referidas interrogações, os colocarmos em diálogo.

\section{Trabalho, mercado e direito}

O trabalho terá sido dos temas que, no campo da teoria de inspiração crítica e do activismo político-social, mais terá beneficiado de empenho analítico ao longo do último século. À parte todos os outros (de inspiração weberiana,

2 De acordo com Boaventura de Sousa Santos (2003), o carácter metonímico da razão jurídica e científica moderna produziu cinco formas de não-existência - o ignorante, o residual, o inferior, o local e o improdutivo. 
funcionalista, etc.), o paradigma marxista gozou de ampla disseminação no meio académico e influenciou a construção de cosmovisões ideológicas que marcaram profundamente a história social, política e económica contemporânea. A relação umbilical do marxismo com o trabalho (como categoria antagónica do capital) estruturou-se a partir de um sujeito político proletário que não só ocupou um estatuto de destaque no pensamento social, como na própria conflitualidade social. Neste contexto, é tão aturada a literatura em torno da centralidade do trabalho na vida social (Offe, 1986) e contra (Schnapper, 1998) ou pelo fim do trabalho (Weeks, 2011; Krisis, 2003), como aquela que se dedica a pensá-lo a partir do direito. O direito do trabalho constituiu uma inovação histórico-normativa crucial (cf. Supiot et al., 2003). É certo que o seu lugar superestrutural convidaria a reduzi-lo a um papel simultaneamente reprodutivo e mistificatório da exploração capitalista. Todavia, as aquisições juslaborais decorrentes da celebração do pacto social, sejam elas lidas como manobra lampeduziana ("é preciso mudar alguma coisa para ficar tudo na mesma") ou sejam elas atribuídas ao poder negocial das forças políticas e sindicais, abriram espaço à consagração de um modelo de Lacordaire ("entre o forte e o fraco, a lei liberta e a liberdade oprime") que fez recuar o laissez-faire enquanto dispositivo material e virtual de justiça. O direito do trabalho tornou-se assim num instrumento privilegiado de protecção - e revelação subjectiva, material e estatutária - da condição trabalhadora nos "predicados da segurança ontológica e previsibilidade legais” (Ferreira, 2009: 9).

A viragem operada pelo Consenso de Washington fez incidir sobre o factor trabalho a sua agenda desagregadora do Estado social, a partir de um consenso económico neoliberal e de um novo padrão de sociabilidade laboral, assente na atomização das relações, na precarização dos vínculos e na atipicidade laborais. A ideia de pleno emprego dá lugar à promoção/gestão da empregabilidade (McDonald e Marston, 2005), a crítica expressiva é cooptada para a neutralização da crítica social (Boltanski e Chiapello, 2001), o reconhecimento é o novo álibi do recuo redistributivo (Fraser, 2002) e o regime de verdade emergente apoia-se numa narrativa de conversão da responsabilidade política em sucesso ou fracasso individual e de conversão do sujeito do trabalho em capital bumano (cf. Matos, 2015). A radicalização deste modelo neoliberal para o que se popularizou como paradigma de austeridade (cf. Leite et al., 2014) veio a confirmar os sinais de uma nova era pós-direito do trabalho e a endogeneização do mercado no tecido social e laboral, nos termos em que António Casimiro Ferreira (2008) o apontara e que viriam a redundar na institucionalização de um direito do trabalho de excepção (Ferreira, 2012).

Enquanto dispositivo de veridicção e de normação (cf. Ewald, 2014), tanto a invocação como a presunção do mercado invadem/constroem quer a 
materialidade do trabalho ${ }^{3}$ quer a argumentação jurídico-judicial que esta suscita (Hespanha, 2012; Ferreira e Pureza, 2014). Por um lado, os fóruns técnico-institucionais que inspiram as fontes oficiais e informais de direito laboral corporizam a "produção comitológica próxima de uma economia do trabalho darwinista, de uma sociologia neofuncionalista e de uma tradição jurídica civilista que têm em comum a ideia geral de que o contrato é a nova forma de vínculo social" (Ferreira, 2008). Por outro lado, enquanto dispositivo de subjectivação - porque gerador de uma convicção sobre o mundo do trabalho e de uma consciência de si nesse mesmo mundo -, o mercado tem um poder de falsificação da realidade que é simultaneamente um poder constituinte do sujeito, influenciando a sua reflexividade, a sua imaginação, a sua identidade e a sua pragmática laboral. Esta dupla dimensão do trabalho - a matriz tecnocrática que o governa e a consciência jurídica em que é vivido (cf. Ewick e Silbey, 1998) - possuem especial relevância para a compreensão da conflitualidade laboral, ajudando a perceber a disposição do sujeito para litigar e a mobilização político-jurídica correlacionada.

Tanto essa disposição para litigar quanto a mobilização político-jurídica correlacionada foram historicamente geridas e impulsionadas por um actor social estruturante do panorama laboral contemporâneo: o sindicato (cf. Dias, 2012). A relação do sindicalismo com o direito é dupla, assentando tanto nas funções assistenciais assumidas com a litigiosidade laboral (Ferreira, 2005; Pedroso, Trincão e Dias, 2002), como nos recursos conflituais e na estrutura de oportunidades político-jurídicas proporcionados pela interlocução e representação colectiva do factor trabalho (McCann, 2006; Turk, 1976). Esta dupla relação inscreve-se em tradições pouco comunicantes no interior dos estudos sociais do direito. A primeira filia-se numa ampla gama de estudos do acesso ao direito e à justiça, iniciada por Cappelletti e Garth (1978), que encontra na pirâmide da litigiosidade (cf. Santos et al., 1996) uma metáfora analítica. A segunda remete para a contentious politics (McAdam, Tarrow e Tilly, 2001) e para o corpus da teoria dos movimentos sociais, onde o direito passou progressivamente a ser observado como um importante recurso estratégico mobilizável na acção colectiva (Israël, 2009).

As transformações que a última década e meia viu acentuar na paisagem normativo-laboral desafiam, de modo próprio, esta dupla dimensão da mediação que o direito opera entre o sujeito e o trabalho. Essas transformações encontram especial preponderância na conjugação da atomização jurídica das relações laborais com a atomização social do factor trabalho, dando cumprimento à chamada sociedade da austeridade (Ferreira, 2012). A dupla fractura do laço jurídico-laboral e do laço sócio-sindical traduz-se assim num exemplo 
“de como a tarefa impossível de encontrar soluções biográficas para contradições sistémicas é imposta aos indivíduos” (Beck, 2007: 685). É precisamente esta tarefa que o mercado aporta e reclama ao estatuto, à matéria e ao sujeito laboral que encontra ressonância analítica na relação entre a psiquiatria e o estatuto, a matéria e o sujeito sexual.

\section{Sexo, psiquiatria e direito}

Se o mercado se encontra com o direito do trabalho na disciplina da produção laboral, a psiquiatria encontra-se com o direito penal na disciplina do desvio sexual: e o desvio sexual torna-se objecto de interesse na exacta medida em que constitui uma fonte de perigosidade. A emergência do princípio da perigosidade e a afirmação da teoria da defesa social ${ }^{4}$ foram um objecto de trabalho que conduziu Michel Foucault a uma retrospectiva dos saberes e dos poderes forenses, detendo-se em particular na confissão judiciária (Foucault, 2014) e interpelando a transição do princípio da responsabilidade, que colocava a tónica na ilicitude do facto, para o princípio da perigosidade, que deslocava a atenção para o sujeito que o cometeu.

A introdução de uma lógica preventiva e precaucionária (cf. Garapon e Salas, 1999: 7-12) nos modos de imaginar e intervir sobre a segurança da população encontra-se na origem de uma aliança entre o direito e a psiquiatria, ao serviço de um projecto de monitorização do sujeito perigoso, sobre o qual era necessário produzir conhecimento científico, avaliar a imputabilidade criminal (cf. Marques, 2007), medir e calcular o nível de ameaça que constitui para a sociedade e definir as medidas reabilitativas e securitárias conformes. A exterioridade do facto ilícito que até então incriminava o sujeito sofre uma viragem introspectiva que dirige a atenção jurídico-penal para o mistério interior do sujeito (Quintais, 2012), atendendo ao que fez, ao que pode potencialmente fazer e ao que a sua liberdade representa para o conjunto populacional. A psiquiatria constituiu o instrumento que, acompanhado pela criminologia e pela antropologia criminal, criou condições de possibilidade para a transformação da regulação penal do desvio.

Se a visibilidade concedida à patologia mental ampliou o marco da inimputabilidade, e se a perigosidade se indexou a essa mesma patologia mental, então a função social do direito descentra-se da punição do crime e alarga-se ao imperativo da defesa da sociedade. Como conclui Foucault (2014: 223), a inauguração do regime de segurança surge quando a graduação da pena deixa de radicar exclusivamente na culpa (princípio da responsabilidade) e adquire

4 Sobre o princípio governamental da defesa social e a perigosidade como fundamento penal, cf. Foucault (2014). 
o propósito governamental de assegurar a protecção conjunta da população (princípio da perigosidade). Torná-lo funcional significa conceber arranjos, profissionalizar agentes e accionar dispositivos institucionais capazes de corresponder ao desafio da verdade do sujeito cujas formas de ser, de estar e de agir destoam, comprometem ou sabotam a maximização do rendimento social e simbólico da população. Foi nesse rendimento social e simbólico que se incrustou e normalizou, de forma tão falsificadora quanto constituinte do sujeito, a ficção da sua integridade, da sua liberdade e da sua autodeterminação sexual, hoje consagradas como o bem jurídico tutelado pelo Estado penal. A protecção jurídica da sexualidade encontra na penetração peniano-vaginal um importante fundamento genealógico, emergindo como referente normativo e descritivo que serve a medição e a determinação do que é ou não é sexual, e em que termos. Esta materialização histórico-forense da tutela sexual não pode ser pensada fora de um princípio de dominação masculina (Bourdieu, 2013) que se encontra formalizado na contratualidade histórico-institucional (o casamento) a partir da qual se concebeu, legitimou, enquadrou e potenciou a produção social de vida. Esta contratualidade reclama na sua base a consciência ontológica e a competência funcional de dois sujeitos-tipo (categorizados como Homem e como Mulher) que o poder jurídico, disciplinar e biopolítico conheceu e regulou, portanto vigiou e puniu, de forma diferente e desigual ao longo da história (cf. Beleza, 2004).

Uma faceta da manifestação desta estrutura dicotómica (presumida e construída) da identidade sexual na interioridade psíquica do sujeito diz respeito à chamada orientação sexual, em particular no modo como interpela a tensão entre norma, desvio e sentido social. Por um lado, a chamada "caça às sexualidades periféricas" (Foucault, 1994: 46) evidencia o encaixe e o peso que o desvio e a perigosidade sexuais ganharam nos tribunais; por outro lado, a preponderância global da missão epistémica da psiquiatria no governo social e judiciário do sujeito moderno abre espaço à sua observação enquanto meio privilegiado de uma psicopolítica (cf. Han, 2015) cujas metáforas/derivas distópicas da patologização da desobediência política ("esquizofrenia progressiva”) ou da patologização da fuga dos escravos ("drapetomania”) marcaram o imaginário sórdido do sujeito dissidente: uma dissidência cuja génese antagonística e performativa evoluiu para um regime de expressão identitária a partir de diferentes categorias - como a categoria homossexual - que transitaram, não sem pesados custos epistemológicos, do universo psiquiátrico para o campo social, político e jurídico.

Ora, não faltam pesquisas empíricas e reflexões conceptuais em torno da construção histórica da homossexualidade que dão conta dos mecanismos normativos e discursivos que a investiram de embaraço, de incerteza e de perigosidade (cf., por exemplo, Weeks, 1991). Todavia, a figura do homossexual, resultante da conversão da prática sodomita numa identidade, numa espécie 
individual (Foucault, 1994: 46-47), é apenas parte de uma ambição maior de produzir conhecimento científico e organizar uma economia semântico-moral da sexualidade que revele e induza uma consciência dos sujeitos sobre si próprios, sobre quem são. A acumulação de conhecimento neste domínio veio originar um subcampo patológico que a psiquiatria viria a embutir, ordenar e detalhar numa gramática parafílica, procurando evidência científica sobre a autenticidade sexual do sujeito - e, com elas, novas classificações forenses investíveis de perigosidade, como a necrofilia, a urofilia, o exibicionismo, o sadismo, a zoofilia, etc. (cf. Bering, 2015). A deslocação do enfoque forense daquilo que seriam práticas avulsas e episódicas para um sujeito cujo ânimo comportamental e coesão biográfica são definidos por esse princípio patológico entronca, assim, num processo de medicalização de um insólito sexual (Foucault, 1994: 48) do qual é preciso defender a sociedade.

A aliança da parafilia, enquanto objecto da tutela psiquiátrica, com o crime sexual, enquanto objecto da tutela jurídica, constitui uma via singular para uma reconstituição crítica do regime de verdade e de justiça inscrito no espectro forense e que tem vindo a simultaneamente produzir e responder a uma ansiedade cognitiva e normativa instanciada pelo imperativo de defesa - e de governabilidade - da sociedade. Exemplo disso mesmo é a imbricação da invenção da infância (Ariès, 1988) e da categorização do sujeito criança com a invenção da pedofilia e a categorização do sujeito patológico, singularizando a problemática no panorama psiquiátrico-penal (cf. Ribeiro, 2016). Esta imbricação reenvia para territórios equívocos e ambíguos da interdição social cujo estudo é imprescindível para aceder ao encontro contemporâneo entre o terror sexual e o pânico moral (Lancaster, 2011; Lowenkron, 2013). O triângulo crime, doença e perigo, que tanto inscreve o tema no mundo forense como é já resultado da sua forensificação, ofereceu os ângulos ao antagonismo social e político partir dos quais se abriu espaço à instalação de uma dinâmica populista cuja vitalidade depende da sua distorção conceptual e cuja utilidade provém dos dividendos explícitos e latentes (Hunter, 2008) que são retirados de uma ambição panóptica sobre o corpo social (Wacquant, 2009: 209-242).

\section{0 sexo e o trabalho como confluência governamental}

A referida funcionalidade da distorção conceptual e os dividendos colhidos desta ambição panóptica encontram tanto na normalização sexual como na conformação laboral um denominador comum que coloca em evidência o lugar histórico que o direito reservou ao espaço-tempo doméstico ${ }^{5}$ e o espaço-

5 O espaço doméstico encontra na diferença sexual e geracional a sua unidade de prática social, no casamento, família e parentesco as suas instituições de base, na maximização da afectividade a sua 
-tempo produtivo ${ }^{6}$ (cf. Santos, 2000): a família constituiu a unidade burguesa de normalização sexual ${ }^{7}$ (cf. Foucault, 1994: 9-10) e a fábrica/empresa constituiu a unidade capitalista de conformação laboral. Cada uma destas unidades dispunha de métodos securitários específicos. O espaço-tempo doméstico baseou-os tanto no direito da família (Singly, 2011: 60) como nos dispositivos de saturação sexual, construídos a partir de uma ética/competência de hetero e autocuidado sexual induzido pela clínica:

"a separação entre os adultos e as crianças, a polaridade estabelecida entre o quarto dos pais e o dos filhos (tornou-se canónica no decorrer do século, quando se começaram a construir habitações populares), a segregação relativa de rapazes e das meninas, as instruções estritas de cuidados a ter com os bebés (aleitamento materno, higiene), a atenção desperta para a sexualidade infantil, supostos perigos da masturbação, a importância atribuída à puberdade, os métodos de vigilância sugeridos aos pais, as exortações, os segredos e os medos, a presença, ao mesmo tempo valorizada e temida, dos criados" (Foucault, 1994: $50)$.

O desvio ao pudor e ao protocolo interditivo da sexualidade converter-se-ia num continuum entre a corrupção moral e o indício parafílico, sendo, portanto, um factor de perigosidade do qual era preciso defender a sociedade. Já o espaço-tempo produtivo encontrou na administração científica das organizações as ferramentas de divisão e racionalização do trabalho que cumpririam uma função disciplinar, rendibilizadora e securitária sobre a máquina operária. A concepção administrativa fayoliana, por exemplo, inseria a despistagem de greves, de dissidência ou de má-disposição nas funções de segurança da empresa, o que envolvia tanto a reparação de uma inundação como a eliminação de qualquer indício de perturbação na paz laboral: “é uma espécie de polícia e de exército do Estado com as funções específicas de manutenção da ordem e defesa da empresa. Com estas funções, a empresa e o pessoal conseguem a segurança e a estabilidade espiritual que necessitam" (Ferreira, Caetano e Neves, 1996: 13).

A identificação e imaginação de um inimigo da sociedade ou de uma possibilidade infecciosa da coesão populacional, perante a ameaça anómica que a concentração urbana auspiciava, cruzou o imperativo industrial do trabalho com a higienização da sexualidade, visando a constituição de um corpo social

dinâmica de desenvolvimento, no patriarcado a sua forma de poder, no direito doméstico a sua forma de produção jurídica e no familismo e cultura familiar a sua forma epistemológica (Santos, 2000: 254). 6 O espaço da produção encontra na classe a sua unidade de prática social, na empresa e na fábrica a sua forma institucional, na exploração o principal mecanismo de poder, na maximização do lucro o seu modo de racionalidade e no produtivismo a sua base epistemológica (Santos, 2000: 254).

7 Atendendo ao movimento sociojurídico de conjugalização, sentimentalização e privatização da família (cf. Singly, 2010; Torres, 2001). 
a um tempo são e produtivo, para o qual a psiquiatria e o mercado viriam reunir as respectivas condições de possibilidade: “e, gradualmente, foi construída uma imagem de um inimigo da sociedade: um inimigo da sociedade que poderia ser o revolucionário, tal como poderia ser o assassino, uma vez que, afinal, os revolucionários às vezes matam” (Foucault, 2014: 221).

As mutações ocorridas na regulação sexual e laboral ao longo do século XX conservaram, cada uma delas, uma comunidade interpretativa que, na sua diversidade interna e porosidade externa, chega ao tempo presente instanciada na psicologia-psiquiatria forense e na comitologia laboral. A viragem da tónica no facto para a tónica no sujeito foi, em momentos e sob ritmos distintos, um processo revolucionário em cada uma delas, criando ou renovando o seu repertório cognitivo e normativo: no quadro psiquiátrico, o já referido acesso ao mistério interior do sujeito (Quintais, 2012) permitiu triangular perigo, doença e crime; no quadro comitológico, a deslocação do racionalismo de matriz weberiana para um enfoque biográfico-motivacional nas competências emocionais e relacionais, na fluidez entre intimidade e profissionalidade. Esta transição da dominação burocrática para a dominação psicopolítica convoca todas as esferas pessoais do sujeito para a missão laboral, submetendo-o a um sistema de vigilância e de potenciação existencial com crescente preponderância na conflitualidade laboral, na estratégia litigatória e na argumentação jurídica. Um caso paradigmático diz respeito aos sistemas de videovigilância colocados em creches e jardins-de-infância ${ }^{8}$, cujo horizonte é assegurar o acesso integral e instantâneo dos pais ao trabalho dos educadores, funcionando como resposta a uma dupla ansiedade, que é de ordem simultaneamente disciplinar-laboral e moral-sexual. Esta mesma dupla ansiedade tem vindo também a ganhar terreno e visibilidade através da expansão da regulamentação anti-assédio. De acordo com Ana Oliveira (2018: 361), o empenho na promoção de códigos de conduta em contexto laboral pode representar quer uma essencialização do sentido da sexualidade, quer uma delegação da respectiva interpretação e regulação para a esfera da autoridade organizacional, conferindo-lhe uma missão ou aspiração pastoral. Trata-se de um processo que envolve o reforço perverso e pantanoso dos poderes disciplinares no governo do sujeito e da sociabilidade no mundo do trabalho, revelando também a importância da invocação sexual para a legitimação - e reivindicação - dessa mesma tutela, que é dupla: laboral e moral. Simultaneamente, Denis Salas sublinha que a crise dos modelos tradicionais de indexação do desvio faz com que, surgindo como:

"verdadeiro mal democrático, o crime sexual [emirja] numa sociedade onde a igualdade das condições acarreta a redução da alteridade. É então difícil 
identificar o inimigo público. Com efeito, os delinquentes sexuais são pessoas vulgares: pais de família, professores, pacíficos reformados, homens políticos, vizinhos anódinos..." (Salas, 1999: 45).

A aparente dissolução da perigosidade no tecido social, ao invés de suscitar a dúvida quanto aos pressupostos da economia política do desvio e da normalidade, traduz-se numa intensificação dessa mesma economia política, multiplicando-se as técnicas de controlo e pretextos de legitimação, na exacta medida em que recursivamente resultam e beneficiam do já referido pânico moral. Exemplo disso mesmo foi a aprovação, em 2015, daquela que veio a ser popularizada como a "lista dos pedófilos", uma iniciativa governamental" cujo objectivo é, entre outras coisas, assegurar que os pais que revelarem "fundado receio" de que um/a condenado/a por abuso sexual, com pena cumprida, resida no seu bairro ou no seu destino de férias, possam ver essa suspeita esclarecida pela polícia (e agir em conformidade).

Esta expansão securitária cruza a suspeita sexual com a sofisticação da exploração laboral através de um padrão de sociabilidade neurótico (cf. Boukalas, 2012), que funciona a partir de um dever de verdade (Foucault, 2014) e de uma relação escorregadia com a presunção de inocência. As fontes, os meios e os fins globais da política, que importa anatomizar, estão longe de ser novos (cf. Wacquant, 2009 ${ }^{10}$ ). A diversidade de incidências - sexuais, laborais e outras - desta mesma motivação e deste mesmo modus operandi torna-se clara na obra de Guy Standing (2014), em particular naquilo que, sob um título provocador, designa como "uma política de inferno". Essa política neofascista (Standing, 2014: 259) e neopastoral (Boukalas, 2012), porque "somos todos polícias", é caracterizada pelo panopticismo inscrito na invasão de espaços que até então, ainda que tensos e porosos, eram vedados como privados, na fabricação de tolerância disciplinar por via da atipicidade/engenharia contratual (cf. Noronha, 2012) e numa hierarquia de valor que sobredetermina quem e quem não ("nos") faz falta ou bem. Enquanto expressões metafóricas, a diabolização do precariado ${ }^{11}$ (Standing, 2014) e a monstrificação do pedófilo (Foucault, 2001; Lowenkron, 2013) constituem o resultado da imbricação de tendências cognitivas e normativas em torno do trabalho e do sexo. Partilham um desíg-

9 Lei n. ${ }^{\circ} 103 / 2015$, de 24 de Agosto.

10 Loïc Wacquant (2009) dedica-lhes, aliás, uma reflexão específica no capítulo "Moralismo e panopticismo punitivo: a caça a agressores sexuais". Ao problematizá-los, integra-os numa leitura mais ampla da intensificação da lógica policial e da perda progressiva e selectiva de terreno garantístico: "cria-se uma base de dados nacional com os ficheiros de delinquentes sexuais, que, além de abolir o tradicional 'direito ao esquecimento' para esta categoria de condenados, inclui as impressões digitais e genéticas de menores, de indivíduos que foram considerados inocentes e de pessoas suspeitas mas não acusadas de ilícitos de natureza sexual; esta medida requer igualmente que antigos condenados por crimes sexuais se registem nas autoridades policiais - aguardando o dia em que serão obrigados a divulgar a sua presença" (Wacquant, 2009: 22).

11 Isto é, "o imigrante, o beneficiário de prestações sociais, o criminoso, o deficiente ou incapacitado" (Standing, 2014: 258). 
nio de combate à perigosidade e conjugam o já referido direito de trabalho de excepção (Ferreira, 2012) com um direito penal do inimigo (Jakobs, 2007), condensáveis no terrorista como sujeito-tipo (cf. Boukalas, 2008). É neste sujeito-tipo que recai o imperativo de controlo da consciência e da imaginação que Laura Lowenkron (2013) designou por criminalização da fantasia. Se a autora identificou esse imperativo no campo jurídico-penal - através da criminalização do consumo de pornografia infantil -, este não deixa de encontrar eco no campo jurídico-laboral. A partir da análise de diferentes guias e manuais anti-assédio, Ana Oliveira recenseou um conjunto de orientações que vão no sentido do "estabelecimento de regras proibitivas de acesso a sites pornográficos ou utilização inapropriada de correio electrónico para envio de mensagens com conteúdos de natureza sexual" (Oliveira, 2018: 226). Proposta em 2015, a criminalização do acesso a sites que incitam ao terrorismo ${ }^{12}$ triangula assim o desígnio anti-terrorismo com o desígnio anti-pedofilia e com o desígnio anti-assédio enquanto projectos de defesa social. E tal como tem sido ponderado para a regeneração psíquica da subjectividade terrorista - uma "reabilitação psicológica [baseada] em esforços para restabelecer a capacidade e a funcionalidade humana na sociedade, [...] para alcançar a auto-eficácia e ser capaz de se reintegrar na sociedade [através do] desenvolvimento da personalidade e do bem-estar dos agressores violentos, a fim de se obter um estado de espírito mais pacífico e atitudes favoráveis à sociedade" (Sukabdi, 2017) -, o ensaio da salvação tem convergido com aquilo que Frank Furedi (2003) considera ser o triunfo de uma "cultura terapêutica": para o desvio sexual, reestruturação cognitiva (cf., como exemplo, Cunha e Gonçalves, 2011) e reabilitação sexual (cf., como exemplo, Kaplan e Krueger, 2012); para o sofrimento laboral, coaching, auto-ajuda (Araújo, 2016: 141-155) e "ciência da felicidade" (Standing, 2014: 249-251).

Esta aproximação crítica ao uso e ao trânsito de alguns dispositivos periciais e regulamentares no governo laboral e sexual nas sociedades contemporâneas, mais do que devolver uma convicção sobre o sentido das transformações em curso, constitui acima de tudo um estímulo para mergulhar na cultura social e simbólica que os torna possíveis e funcionais à vida colectiva. Esta realidade aporta, assim, um duplo desafio à investigação sociológica: por um lado, a tarefa de compreender da sua incrustação tanto nos mecanismos de consagração, quanto em muitas das categorias que pontuam na resistência que lhe é oferecida; e, por outro lado, o objectivo de prosseguir a pesquisa em torno quer do lugar das ciências cognitivas no governo da normalidade

12 Cf. a notícia "Aceder a sites que incitem ao terrorismo passa a ser crime", de 19 de Fevereiro de 2015 [Online], disponível em: http://expresso.sapo.pt/sociedade/aceder-a-sites-que-incitem-ao-terrorismo-passa-a-ser-crime=f911578\#ixzz3SDFIA2MX [consultado em 22-12-2018]. 
sociolaboral ${ }^{13}$, quer da progressiva influência do mercado no governo da normalidade sócio-sexual ${ }^{14}$.

\section{Referências bibliográficas}

AMADO, João Leal (2013), "O direito do trabalho, a crise e a crise do direito do trabalho". Revista Direito e Desenvolvimento João Pessoa, 4 (2), 163-186.

ARAÚJO, António (2016), Da direita à esquerda: cultura e sociedade em Portugal, dos anos 80 à actualidade, Porto Salvo, Saída de Emergência.

ARIÈS, Philippe (1988), A criança e a vida familiar no Antigo Regime, Lisboa, Relógio D’Água.

BATAILLE, Georges (2012), As lágrimas de Eros, Lisboa, Sistema Solar.

BAYER, Ronald (1987), Homosexuality and American psychiatry: the politics of diagnosis, Princeton, Princeton University Press.

BECK, Ulrich (2007), "Beyond class and nation: reframing social inequalities in a globalizing world", The British Journal of Sociology, 58 (4), 679-705.

BELEZA, Teresa Pizarro (2004), "Anjos e Monstros: a construção das relações de género no Direito Penal”, Revista Ex Aequo, 10, 29-40.

BERING, Jesse (2015), Perversões: os comportamentos sexuais desviantes, Lisboa, Círculo de Leitores.

BLYTH, Mark (2013), Austerity: the history of a dangerous idea, New York, Oxford University Press.

BOLTANSKI, Luc; CHIAPELLO, Ève (2001), Le nouvel esprit du capitalism, Paris, Gallimard.

BOUKALAS, Christos (2008), "Counterterrorism legislation and the US state form: authoritarian statism, phase III", Radical Philosophy, 151, 31-41.

BOUKALAS, Christos (2012), "Government by experts: counterterrorism intelligence and democratic retreat", Critical Studies on Terrorism, 5 (2), 227-296.

BOURDIEU, Pierre (2013), A Dominação Masculina, Lisboa, Relógio D’Água.

CAPPELLETTI, Mauro; GARTH, Bryant (orgs.) (1978), Access to justice: a world survey, Alphen aan den Rijn, Sijthoff and Noorhoff.

CUNHA, Olga; GONÇALVES, Rui Abrunhosa (2011), “Tratamento de Agressores Domésticos: o Programa de Promoção e Intervenção com Agressores Conjugais”, Revista do Ministério Público, 127, 179-204.

DEAN, Mitchell (2014), “Michel Foucault's 'apology' for neoliberalism”. Journal of Political Power, 7 (3), 433-442.

DERRIDA, Jacques (2009), Vadios, Coimbra, Palimage.

DIAS, Hugo (2012), Sindicalismo de Movimento Social? Experiências de renovação da prática sindical num contexto de transição de paradigma produtivo. Tese de Doutoramento, Coimbra, Faculdade de Economia, Universidade de Coimbra.

EWALD, François (2014), “Juridiction et véridiction”, Grief, 1, 229-233.

FERREIRA, António Casimiro (2005), Trabalho procura Justiça: os tribunais de trabalho na sociedade portuguesa, Coimbra, Almedina.

13 Veja-se, a título de exemplo, a problemática da validação psiquiátrica do assédio enquanto ilicitude laboral (cf. Oliveira, 2017).

14 Veja-se, a título de exemplo, a problemática do "índice gay" como dispositivo governamental (cf. Ribeiro, 2017). 
FERREIRA, António Casimiro (2008), "Flexigurança e princípio da desconfiança". Revista do SNESup, 27 [Online], disponível em: http://www.snesup.pt/cgi-bin/artigo. pl?id=EkElEkpuVpUnejEJTb [consultado em: 18-11-2018].

FERREIRA, António Casimiro (2009), Da sociedade precária à sociedade digna: balanço da evolução social em Portugal (2003-2008), Coimbra, Centro de Estudos Sociais da Universidade de Coimbra.

FERREIRA, António Casimiro (2012), Sociedade da austeridade e direito do trabalho de exceção, Porto, Vida Económica.

FERREIRA, António Casimiro; PUREZA, José Manuel (2014), “Estado de Direito ou Estado de Exceção: a justiça constitucional face ao questionamento do Estado Social", in José Reis (org.), A economia política do retrocesso: crise, causas e objectivos, Coimbra, Almedina, 283-323.

FERREIRA, José Maria Carvalho; Caetano, António; Neves, José Gonçalves das (1996), Psicossociologia das Organizações, Lisboa, McGraw-Hill.

FOUCAULT, Michel (1994), História da sexualidade I: vontade de saber, Lisboa, Relógio d'Água.

FOUCAULT, Michel (2001), Os anormais, São Paulo, Martins Fontes.

FOUCAULT, Michel (2009), Sécurité, territoire, population, Paris, Gallimard.

FOUCAULT, Michel (2010), Nascimento da biopolítica, Lisboa, Edições 70.

FOUCAULT, Michel (2014), Wrong-doing, truth-telling: the function of avowal in justice, Chicago, University of Chicago Press.

FRASER, Nancy (2002), “A justiça social na globalização: redistribuição, reconhecimento e participação”, Revista Crítica de Ciências Sociais, 63, 7-20.

FUREDI, Frank (2003), Therapy culture: cultivating vulnerability in an uncertain age, London, Routledge.

GARAPON, Antoine; SALAS, Denis (1999), "O 'Salafrário' da Democracia”, in Antoine Garapon; Denis Salas (orgs.), A justiça e o mal, Lisboa, Instituto Piaget, 7-12.

HAN, Byung-Chul (2015), Psicopolítica, Lisboa, Relógio d’Água.

HESPANHA, António Manuel (2012) “A revolução neoliberal e a subversão do 'modelo jurídico'. Crise, Direito e Argumentação Jurídica”, Revista do Ministério Público, 130, 9-80.

HUNT, Alan; WICKHAM, Gary (1994), Foucault and law: towards a sociology of law as governance, London, Pluto Press.

HUNTER, James (2008), "The political use and abuse of the 'pedophile". Journal of Homosexuality, 55 (3), 350-387.

ISRAËL, Liora (2009), L'Arme du Droit, Paris, Presses de Sciences Po.

JAKOBS, Günther (2007), Direito Penal do Inimigo: noções e críticas, Porto Alegre, Livraria do Advogado.

KAPLAN, Meg S.; KRUEGER, Richard B. (2012), "Cognitive-behavioral treatment of the parafilias”. Israel Journal of Psychiatry and Related Sciences, 49, 291-296.

KRISIS (2003), Manifesto contra o trabalho, Lisboa, Antígona.

LAFARGUE, Paul (2016 [1880]), O direito à preguiça, Lisboa, Antígona.

LANCASTER, Roger N. (2011), "Panic: a guide to the uses of fear", in Roger N. Lancaster, Sex Panic and the Punitive State, Berkeley, University of California Press, 23-38.

LEBRUN, François (1983), A vida conjugal no Antigo Regime, Lisboa, Edições Rolim.

LEITE, Jorge; COSTA, Hermes Augusto; SILVA, Manuel Carvalho da; ALMEIDA, João Ramos (2014), "Austeridade, reformas laborais e desvalorização do trabalho", in José Reis (org.), A economia política do retrocesso: crise, causas e objectivos, Coimbra, Almedina, 127-188.

LOWENKRON, Laura (2013), "A cruzada antipedofilia e a criminalização das fantasias sexuais”. Sexualidad, Salud y Sociedad, 15, 37-61. 
MARQUES, Tiago Pires (2007), "Da personalidade criminosa ao criminoso perverso. Psiquiatras, juristas e teólogos na crise do liberalismo", Ler História, 53, 35-61.

MATOS, José Nuno (2015), O Operário em Construção: do empregado ao precário, Porto, Deriva Editores.

MCADAM, Doug; TARROW, Sidney; TILLY, Charles (2001), Dynamics of Contention, Cambridge, Cambridge University Press.

MCCANN, Michael W. (2006), "Law and social movements: contemporary perspectives", Annual Review of Law and Social Science, 2, 17-38.

MCDONALD, Catherine, MARSTON, Greg (2005), "Workfare as welfare: governing unemployment in the advanced liberal state”, Critical Social Policy, 25 (3), 374-401.

NORONHA, Ricardo (2012), "Precariedade: modos de usar”, in José Nuno Matos; Nuno Domingos (orgs.), Novos proletários: a precariedade entre a 'classe média' em Portugal, Lisboa, Edições 70 / Le Monde Diplomatique, 29-42.

OFFE, Claus (1986), Disorganized capitalism: contemporary transformations of work and politics, Oxford, Basil Blackwell.

OLIVEIRA, Ana (2017), A expressão normativa do assédio: aproximações sociojurídicas à sexualidade. Tese de Doutoramento, Coimbra, Faculdade de Letras, Universidade de Coimbra.

PASQUINO, Pasquale (1991), "Criminology: the birth of a special knowledge", in Graham Burchell; Colin Gordon; Peter Miller (orgs.), The Foucault Effect: studies in governamentality, Chicago, University of Chicago Press, 235-250.

PEDROSO, João; Trincão, Catarina; Dias, João Paulo (2002), O Acesso ao Direito e à Justiça: um direito fundamental em questão, Coimbra, Centro de Estudos Sociais / Observatório Permanente da Justiça Portuguesa.

PRECIADO, Beatriz (2013), “Teoria queer: notas para una política de lo anormal o contra-historia de la sexualidade”, Revista Observaciones Filosóficas, 15.

QUINTAIS, Luís (2012), Mestres da verdade invisivel no arquivo da psiquiatria forense portuguesa, Coimbra, Imprensa da Universidade de Coimbra.

RIBEIRO, Tiago (2016), “Sujeito ao direito: em torno da confissão e da perícia”, in José Neves (org.), Quem Faz a História: Ensaios sobre o Portugal Contemporâneo, Lisboa, Tinta-daChina, 133-146.

RIBEIRO, Tiago (2017), "Governo por indicadores como indicador de governo: pressupostos e enviesamentos na captação do social”, in Sara Moreno Pires, Alexandra Aragão, Teresa Fidélis, Ireneu Mendes (orgs.), Indicadores de desenvolvimento sustentável: instrumentos estratégicos e inovadores para municípios sustentáveis. O caso de Estarreja, Aveiro, Instituto Jurídico e Universidade de Aveiro, 396-410.

SALAS, Denis (1999), "O delinquente sexual”, in Antoine Garapon; Denis Salas (orgs.), A justiça e o mal, Lisboa, Instituto Piaget, 45-74.

SANTOS, Boaventura de Sousa (2000), A Crítica da Razão Indolente: contra o desperdício da experiência, Porto, Afrontamento.

RIBEIRO, Tiago (2016), “Sujeito ao direito: em torno da confissão e da perícia”, in José Neves (org.), Quem Faz a História: Ensaios sobre o Portugal Contemporâneo, Lisboa, Tinta-daChina, 133-146.

RIBEIRO, Tiago (2017), “Governo por indicadores como indicador de governo: pressupostos e enviesamentos na captação do social”, in Sara Moreno Pires, Alexandra Aragão, Teresa Fidélis, Ireneu Mendes (orgs.), Indicadores de desenvolvimento sustentável: instrumentos estratégicos e inovadores para municípios sustentáveis. O caso de Estarreja, Aveiro, Instituto Jurídico e Universidade de Aveiro, 396-410. 
SALAS, Denis (1999), “O delinquente sexual”, in Antoine Garapon; Denis Salas (orgs.), A justiça e o mal, Lisboa, Instituto Piaget, 45-74.

SANTOS, Boaventura de Sousa (2000), A Crítica da Razão Indolente: contra o desperdício da experiência, Porto, Afrontamento.

SANTOS, Boaventura de Sousa (2003), "Para uma sociologia das ausências e uma sociologia das emergências”, in Boaventura de Sousa Santos (org.), Conhecimento prudente para uma vida decente: "Um discurso sobre as ciências» revisitado, Porto, Afrontamento, 735-775.

SANTOS, Boaventura de Sousa; Marques, Maria Manuel Leitão; Pedroso, João; Ferreira, Pedro (1996), Os tribunais nas sociedades contemporâneas. O caso português, Porto, Afrontamento.

SCHNAPPER, Dominique (1998), Contra o fim do trabalho, Lisboa, Terramar.

SENNETT, Richard (2001), A corrosão do carácter: as consequências pessoais do trabalho no novo capitalismo, Lisboa, Terramar.

SINGLY, François (2011), Sociologia da Família Contemporânea, Lisboa, Edições Texto \& Grafia.

STANDIG, Guy (2014), O precariado: a nova classe perigosa, Lisboa, Editorial Presença.

STREECK, Wolfgang; Schäfer, Armin (2013), Politics in the age of austerity, London, Polity.

SUKABDI, Zora A. (2017), "Psychological rehabilitation for ideology-based terrorism offenders". International Journal of Neurorehabilitation, 4 (1), 247-255.

SUPIOT, Alain (2005), "O direito do trabalho ao desbarato no 'mercado das normas"”. Questões laborais, 26, 121-144.

SUPIOT, Alain, et al. (2003), Transformações do trabalho e futuro do direito do trabalho na Europa, Coimbra, Coimbra Editora.

TORRES, Anália (2001), Sociologia do Casamento: a Família e a Questão Feminina, Oeiras, Celta.

TURK, Austin T. (1976), "Law as a Weapon in Social Conflict”, Social Problems, 23 (3), 276-291.

WACQUANT, Loïc (2009), Punishing the poor: the neoliberal government of social insecurity, Durham and London, Duke University Press.

WEEKS, Jeffrey (1991), Against nature: essays on history, sexuality and identity, London, Rivers Oram Press.

WEEKS, Kathi (2011), The problem with work: feminism, marxism, antiwork politics and postwork imaginaries, Durham and London, Duke University Press. 